\title{
Hospitalization among street-involved youth who use illicit drugs in Vancouver, Canada: a longitudinal analysis
}

\author{
Derek C. Chang ${ }^{1,2}$, Launette Rieb ${ }^{1,2}$, Ekaterina Nosova ${ }^{1}$, Yang Liu' ${ }^{1}$, Thomas Kerr ${ }^{1,3}$ and Kora DeBeck ${ }^{1,4^{*}}$
}

\begin{abstract}
Background: Street-involved youth who use illicit drugs are at high risk for health-related harms; however, the profile of youth at greatest risk of hospitalization has not been well described. We sought to characterize hospitalization among street-involved youth who use illicit drugs and identify the most frequent medical reasons for hospitalization among this population.
\end{abstract}

Methods: From January 2005 to May 2016, data were collected from the At-Risk Youth Study (ARYS), a prospective cohort study of street-involved youth in Vancouver, Canada. Multivariable generalized estimating equation (GEE) was used to identify factors associated with hospitalization.

Results: Among 1216 participants, 373 (30.7\%) individuals reported hospitalization in the previous 6 months at some point during the study period. The top three reported medical reasons for hospital admission were the following: mental illness (37.77\%), physical trauma (12.77\%), and drug-related issues (12.59\%). Factors significantly associated with hospitalization were the following: past diagnosis of a mental illness (adjusted odds ratio $[\mathrm{AOR}]=1.85 ; 95 \%$ confidence interval $[95 \% \mathrm{Cl}] 1.47-2.33)$, frequent cocaine use ( $\mathrm{AOR}=2.15 ; 95 \% \mathrm{Cl} 1.37-3.37)$, non-fatal overdose $(\mathrm{AOR}=1.76 ; 95 \% \mathrm{Cl}$ 1.37-2.25), and homelessness ( $\mathrm{AOR}=1.40 ; 95 \% \mathrm{Cl} 1.16-1.68)$ (all $p<0.05)$.

Conclusions: Findings suggest that mental illness is a key driver of hospitalization among our sample. Comprehensive approaches to mental health and substance use in addition to stable housing offer promising opportunities to decrease hospitalization among this vulnerable population.

Keywords: Youth, Hospitalization, Mental illness, Drug overdose, Homeless, Cocaine

\section{Background}

Youth who are street-involved, defined as being homeless or using services for homeless youth, experience excess morbidity and mortality relative to the general population of adolescents and young adults $[1,2]$. Many health concerns have been identified among this population, including sexually transmitted infections, mental illnesses, intentional and unintentional injuries, and substance use $[3,4]$. Several health issues are directly related to substance use, including overdoses, infections, and psychological

\footnotetext{
* Correspondence: uhri-kd@cfenet.ubc.ca

${ }^{1}$ British Columbia Centre on Substance Use, British Columbia Centre for Excellence in HIV/AIDS, St. Paul's Hospital, 608-1081 Burrard Street, Vancouver, BC V6Z 1Y6, Canada

${ }^{4}$ School of Public Policy, SFU Harbour Centre, Simon Fraser University, 515

West Hastings Street, Suite 3271, Vancouver, BC V6B 5K3, Canada

Full list of author information is available at the end of the article
}

distresses [4]. The experience of homelessness and mental illnesses, such as conduct disorders, anxiety disorders, and mood disorders, which are prevalent among homeless youth, may also contribute to or exacerbate health issues among this population [5]. Despite multiple health vulnerabilities, numerous barriers to accessing care exist, including inadequate transportation, cost, fear of judgment, and lack of trust [6,7]. Consequently, street-involved youth are often reluctant to engage with health services and frequently delay seeking help until their health problems deteriorate, which increases the risk of hospitalization $[6,8]$. This tendency also contributes to the economic burden of delaying care among this population [4, 9].

Hospitalization among adult homeless populations has been well studied, while there is a paucity of similar research among homeless youth populations [10-12]. In 
the USA, it has been documented that acute medical conditions (primarily infections), mental illness, substance use, and injuries are the most common reasons for hospitalization among homeless youth [10]. To our best knowledge, no study has longitudinally examined hospital admissions among street-involved youth who use drugs in a Canadian setting with universal health care. In the context of growing concerns of homelessness and its related burdens, especially overdoses, among youth in North America [12], we sought to update the knowledge of the most common medical reasons for hospital admission and characterize hospitalization among street-involved youth who use drugs. We hope the findings can inform policy makers and healthcare workers to provide more effective interventions to prevent more serious health conditions requiring hospitalization among this vulnerable population and subsequently reduce the related economic burden.

\section{Methods}

The At-Risk Youth Study (ARYS) began in 2005 and is an ongoing open prospective cohort study of street-involved youth in Vancouver, Canada. This study has been described in detail previously [13]. In brief, snowball sampling and street-based outreach as well as self-referral are used to recruit participants into the study. Persons between 14 and 26 years of age who have used illicit drugs other than or in addition to cannabis in the past 30 days and provide informed consent are eligible to participate. At baseline and semiannually thereafter, participants complete an interviewer-administered questionnaire. The questionnaire elicits sociodemographic data as well as information regarding participants' substance use and other behavioral and socioeconomic data such as housing and engagement with health and social services. All participants receive a monetary stipend of $\$ 30$ Canadian Dollars after each interview (in June 2016, the stipend amount was increased to \$40). The University of British Columbia/Providence Health Care Research Ethics Board approved the study.

Data for this study was collected between January 2005 and May 2016. The primary outcome was self-reported hospitalization during the preceding 6 months. Specifically, participants were asked, "Have you been admitted to hospital in the last six months (yes vs. no)?" Participants who responded affirmatively were then asked to report the reason for hospitalization. These descriptive data were analyzed and grouped to identify the most common reasons for hospitalization among this sample.

To characterize hospitalization (which was selfreported and captured admissions to hospital), we considered a range of variables potentially associated with hospitalization. These were all measured within the preceding 6 months and included the following: any injection drug use, daily heroin use, daily non-medical prescription opioid use, daily crystal methamphetamine use, daily cocaine use, daily crack use, non-fatal overdoses, homelessness, living in the Downtown Eastside (DTES) neighborhood (Vancouver's drug use epicenter), and incarceration (being in detention, prison, or jail). The following sociodemographic characteristics measured at baseline were also considered: age, gender, ethnicity, self-identified as LGBT (lesbian, gay, bisexual, and transgender), and self-reported diagnosis of a mental health illness. Covariates were selected based on review of the prior available literature [2, 3, 14].

Since analyses of factors potentially associated with hospitalization included serial measures for each subject, we used generalized estimating equations (GEE) for binary outcomes with logit link function for the analysis of correlated data. These methods determine factors associated with hospitalization throughout the greater than 11-year follow-up period and provide standard errors adjusted by multiple observations per person using an exchangeable correlation structure. Therefore, this analysis considered data from every participant follow-up visit. First, we used GEE bivariate analysis to determine factors associated with hospitalization. To adjust for potential confounding, all variables that were significant at $p<0.10$ level in GEE bivariate analyses were considered in a full model. Quasi-likelihood under the Independence model Criterion (QIC) statistic with a backward model selection procedure was used to screen all possible combinations of candidate variables and identify the model with the best overall fit as indicated by the lowest QIC value. Analyses were performed using $\mathrm{R}$ version 3.2.4 ( $\mathrm{R}$ Core Team (2016). R: A language and environment for statistical computing. R Foundation for Statistical Computing, Vienna, Austria). All $p$ values were two-sided, and tests were considered significant at $p<0.05$.

\section{Results}

Overall, 1216 individuals completed follow-up visits including 380 (31\%) female and 819 (67\%) Caucasian youth. The median age of participants at baseline was 22 years (interquartile range $[\mathrm{IQR}]=20-24$ ). Participants contributed 4956 observations during the study period. The median number of follow-up visits was 3 (IQR $=1-5$ ), and the median number of months between study followup was $6(\mathrm{IQR}=6-8)$. Participants who did not return for a subsequent follow-up visit after baseline were significantly less likely to identify as LGBTQ and significantly more likely to be $\mathrm{HCV}$ positive (both $p<0.05$ ), though no other significant differences were observed between the two groups. Among our sample, 373 individuals (30.7\%) reported being hospitalized at some point during the study period. Over the study period, these 373 participants 
contributed a total of $564(11.4 \%)$ study observations that included a report of hospitalization. At baseline, 900 participants (74\%) reported being homeless. At the most recent study visit during the study period, 111 of 272 participants (41\%) reported being homeless (55\% of the hospitalized group and $45 \%$ of those who reported no hospitalization during the study period).

Table 1 presents sociodemographic characteristics, drug use and socioeconomic factors at baseline, comparing those who did and did not report hospitalization during follow-up. Table 2 displays unadjusted and adjusted odds ratios for hospitalization and variables of interest. The adjusted multivariate model demonstrates that the youth who had a past diagnosis of a mental illness (AOR, 1.85; 95\% CI, 1.47-2.33), used cocaine daily (AOR, 2.15; 95\% CI, 1.37-3.37), experienced a non-fatal overdose (AOR, 1.76; 95\% CI, 1.37-2.25), or were homeless (AOR, 1.40; 95\% CI, 1.16-1.68) were significantly more likely to report recent hospitalization within the previous 6 months.

Table 3 displays the top medical reasons for hospitalization. Mental illness (37.77\%) was the most common medical condition followed by physical trauma (12.77\%) and drug-related conditions (12.59\%).

\section{Discussion}

Based on this prospective cohort of street-involved youth who use drugs, homelessness, past diagnosis of a mental illness, frequent cocaine use, and non-fatal overdose were significantly associated with hospitalization. Among the medical reasons for hospital admission, mental illnesses, physical trauma, and drug-related conditions were the most common reasons.

Our finding that homelessness was significantly associated with youth hospitalization is consistent with previous literature indicating that homelessness and unstable housing not only increase hospital use but also increase the length of hospital stay $[9,14]$. Conversely, the longer their stay in the hospital, the more likely the youth could lose their housing. Our results build on a significant body of research highlighting the essential role of stable housing in supporting the health and well-being of vulnerable populations. Evidence also suggests that the relationship between mental illness and homelessness can be multidirectional. Homelessness is known to directly undermine mental health [15], and mental illness can directly contribute to becoming homeless [15]. Regardless of the direction of the relationship, a multisite randomized controlled study demonstrates that a "housing first" approach (combined with assertive community treatment or intensive case management) improves housing stability among homeless youth with mental illnesses [16].

Our study also shows that a history of mental illness was significantly associated with hospitalization among street-involved youth, and mental illness was the number one reason for hospital admission. While this correlation has been established among adult homeless populations, it has been less clear among homeless youth [17]. Previous literature demonstrates that the prevalence of psychiatric disorders is high (88\%) among homeless youth, but only

Table 1 Baseline characteristics (reported at time of study enrolment) of street-involved youth who report hospitalization during study follow-up: At Risk Youth Study (ARYS), Vancouver, British Columbia, 2005-2016 ( $n=1216$ )

\begin{tabular}{|c|c|c|c|}
\hline \multirow[t]{2}{*}{ Characteristic } & \multicolumn{2}{|l|}{ Hospitalized } & \multirow[b]{2}{*}{$p$ value } \\
\hline & Yes (\%) $(n=151)$ & No $(\%)(n=1065)$ & \\
\hline Median age, years (IQR) & $22(20-23)$ & $22(20-24)$ & 0.354 \\
\hline Female gender & $54(35.8)$ & $326(30.6)$ & 0.201 \\
\hline Caucasian ethnicity & $102(67.5)$ & $717(67.3)$ & 0.993 \\
\hline Identified as LGBT & $120(79.5)$ & $872(81.9)$ & 0.301 \\
\hline Mental illness history & $91(60.3)$ & $542(50.9)$ & $0.031^{*}$ \\
\hline Any injection drug use $\mathrm{e}^{\ddagger}$ & $54(35.8)$ & $348(32.7)$ & 0.460 \\
\hline Daily heroin use $\mathrm{e}^{\ddagger}$ & $24(15.9)$ & $112(10.5)$ & $0.046^{*}$ \\
\hline Daily prescription opioid use $e^{\ddagger}$ & $6(4.0)$ & $36(3.4)$ & 0.694 \\
\hline Daily crystal meth use $\mathrm{e}^{\ddagger}$ & $25(16.6)$ & $137(12.9)$ & 0.223 \\
\hline Daily cocaine use $\mathrm{e}^{\ddagger}$ & $8(5.3)$ & $29(2.7)$ & 0.080 \\
\hline Daily crack use $\mathrm{e}^{\ddagger}$ & $29(19.2)$ & $157(14.7)$ & 0.166 \\
\hline Non-fatal overdose ${ }^{\ddagger}$ & $31(20.5)$ & $139(13.1)$ & $0.015^{*}$ \\
\hline Homeless $^{\ddagger}$ & $122(80.8)$ & $778(73.1)$ & 0.052 \\
\hline Living in the DTES ${ }^{\ddagger}$ & $48(31.8)$ & $303(28.5)$ & 0.397 \\
\hline Incarcerated ${ }^{\ddagger}$ & $27(17.9)$ & 190 (17.8) & 0.974 \\
\hline
\end{tabular}


Table 2 Bivariable and multivariable GEE analyses of factors associated with hospitalization among street-involved youth: At-Risk Youth Study (ARYS), Vancouver, British Columbia, 2005$2016(n=1216)$

\begin{tabular}{|c|c|c|c|}
\hline Characteristic & $\begin{array}{l}\text { Unadjusted OR } \\
(95 \% \mathrm{Cl})\end{array}$ & $\begin{array}{l}\text { Adjusted OR } \\
\left(95 \% \mathrm{Cl}^{\dagger}\right.\end{array}$ & $p$ value \\
\hline Age (per year older) & $\begin{array}{l}1.00 \\
(0.97-1.02)\end{array}$ & & \\
\hline Female gender & $\begin{array}{l}0.90 \\
(0.72-1.13)\end{array}$ & & \\
\hline Caucasian ethnicity & $\begin{array}{l}1.11 \\
(0.88-1.40)\end{array}$ & & \\
\hline Identified as LGBT & $\begin{array}{l}0.89 \\
(0.68-1.18)\end{array}$ & & \\
\hline Mental illness history & $\begin{array}{l}1.87 \\
(1.50-2.35)\end{array}$ & $1.85(1.47-2.33)$ & $<0.001^{*}$ \\
\hline Any injection drug use $\mathrm{e}^{\ddagger}$ & $\begin{array}{l}1.29 \\
(1.05-1.57)\end{array}$ & & \\
\hline Daily heroin use $\mathrm{e}^{\ddagger}$ & $\begin{array}{l}1.11 \\
(0.87-1.41)\end{array}$ & & \\
\hline $\begin{array}{l}\text { Daily prescription opioid } \\
\text { use }\end{array}$ & $\begin{array}{l}1.46 \\
(0.88-2.42)\end{array}$ & & \\
\hline Daily crystal meth use $\mathrm{f}^{\ddagger}$ & $1.13(0.88-1.45)$ & & \\
\hline Daily cocaine use $e^{\ddagger}$ & $\begin{array}{l}2.36 \\
(1.50-3.70)\end{array}$ & $2.15(1.37-3.37)$ & $0.001^{*}$ \\
\hline Daily crack use $e^{\ddagger}$ & $\begin{array}{l}1.13 \\
(0.84-1.50)\end{array}$ & & \\
\hline Non-fatal overdose ${ }^{\ddagger}$ & $\begin{array}{l}1.98 \\
(1.55-2.51)\end{array}$ & $1.76(1.37-2.25)$ & $<0.001^{*}$ \\
\hline Homeless ${ }^{\ddagger}$ & $\begin{array}{l}1.41 \\
(1.18-1.68)\end{array}$ & $1.40(1.16-1.68)$ & $<0.001^{*}$ \\
\hline Living in the DTES ${ }^{\ddagger}$ & $\begin{array}{l}1.11 \\
(0.90-1.36)\end{array}$ & & \\
\hline Incarceration ${ }^{\ddagger}$ & $\begin{array}{l}1.11 \\
(0.87-1.43)\end{array}$ & & \\
\hline
\end{tabular}

${ }^{*} p<0.05$

${ }^{\dagger}$ Variables significant at $p<0.10$ in bivariate models were eligible for possible inclusion in the multivariable model; variables included in the final multivariable model were identified using a backward selection approach to minimize the Quasi-likelihood under the Independent model Criterion (QIC) ${ }^{\ddagger}$ During the preceding 6 months

Table 3 Top five medical reasons for hospitalization among street-involved youth: At-Risk Youth Study (ARYS), Vancouver, British Columbia, 2005-2016 ( $n=373$ participants who contributed 564 study observations)

\begin{tabular}{ll}
\hline Medical condition & $N(\%)$ \\
\hline Mental illness & $213(37.77)$ \\
Physical trauma & $72(12.77)$ \\
Drug related & $71(12.59)$ \\
Infection related & $48(8.51)$ \\
Pregnancy related & $35(6.21)$
\end{tabular}

Based on total number of reports of hospitalization, not number of participants
$31 \%$ had accessed any form of mental health services, including in community clinics, emergency rooms, or addiction treatment [18]. Our findings therefore point to the importance of improving access to mental health services in the community among street-involved youth.

Substance use-related issues, specifically frequent cocaine use and non-fatal overdoses, were also associated with youth hospitalization among our sample. Evidence has shown that illicit substance use is associated with increased risk of hospitalization [19]. Our study contributes to the knowledge that cocaine in particular is associated with increased risk of hospitalization. Previous literature also highlights other risks associated with stimulant use among homeless youth, particularly risky sexual behaviors and incarceration [20]. Given these harms, it is particularly concerning that evidence-based treatment options for stimulant use disorder are limited; innovation in this area is needed.

Moreover, non-fatal overdose was independently associated with hospitalization among street-involved youth. Drug-related overdoses continue to increase among young adults and adolescents who use drugs, and opioid overdoses have risen at an alarming rate in recent years in Vancouver [21-23]. Extensive morbidity is also associated with non-fatal overdoses, including physical injury, falling, or personal assaults [24]. Overdose prevention and harm reduction programs, such as peer-based education and naloxone training, as well as expanding treatment options, can be expected to help decrease youth hospitalization $[25,26]$.

In our study among street-involved youth engaged in illicit substance use, over $50 \%$ reported a history of mental illness at baseline indicating that the prevalence of dual diagnosis among our sample is high. This is consistent with the literature that reports the prevalence of dual diagnosis between 35 and $76 \%$ among homeless youth [4]. A recent study also found that precariously housed youth were $48 \%$ more likely to be diagnosed with dual diagnosis [27]. Given the prevalence of youth with dual diagnosis, it is essential to integrate interventions such as systematic screening for dual diagnosis and building mental health and addiction training into youth-serving organizations [27]. Early diagnosis can also increase the likelihood that youth will access care before the condition progresses further and requires hospitalization.

When trying to access healthcare, youth are known to face several barriers including financial (lack of free transportation or health insurance), structure (unable to obtain birth certificate or ID), and personal (lack of knowledge or fear of judgment from healthcare professionals) $[4,6,7]$. Thus, it is critical to ensure that youth do not face restrictive barriers when trying to access services, so youth can access early interventions to prevent eventual hospitalizations. 
There are several limitations to this study. First, the ARYS cohort is not a random sample. Therefore, study findings may not generalize to other populations. Second, the results are based on self-reported data, which may be affected by recall bias and socially desirable responding. Also, they may not accurately reflect the medical reasons for hospitalization. Third, as with all observation studies, the independent associations that we found could have been influenced by other confounding variables.

\section{Conclusions}

Our study suggests that mental illnesses were a key driver of hospitalization among street-involved youth. Frequent cocaine use, non-fatal drug overdose, and homelessness were also significantly associated with hospitalization. Based on these findings, promising opportunities to prevent hospitalization may include ensuring stable housing in line with the "housing first" approach, increasing access to youth-friendly mental health and addiction treatment services, providing overdose prevention education and harm reduction measures, and improving early identification of dual diagnosis and access to care.

\section{Acknowledgements}

The authors thank the study participants for their contribution to the research as well as the current and past researchers and staff. We would specifically like to thank Evan Wood, Carly Hoy, Jennifer Matthews, Deborah Graham, Peter Vann, Steve Kain, Tricia Collingham, Marina Abramishvili, and Ana Prado for their research and administrative assistance. We would also like to acknowledge our funding agencies, including Canadian Institutes of Health Research, Michael Smith Foundation for Health Research, St. Paul's-Providence Health Care, and US National Institutes of Health.

\section{Funding}

The study was supported by the US National Institutes of Health (U01DA038886) and the Canadian Institutes of Health Research (MOP-102742). Dr. Chang is supported by the Canadian Addiction Medicine Research Fellowship funded by the US National Institutes of Health (R25DA037756). Dr. DeBeck is supported by a MSFHR/St. Paul's Hospital Foundation - Providence Health Care Career Scholar Award and a Canadian Institutes of Health Research New Investigator Award.

\section{Availability of data and materials}

The datasets used and/or analyzed during the current study are available from the corresponding author on a reasonable request.

\section{Authors' contributions}

DC, TK, and KD designed the study. DC conducted the literature review and wrote the first draft of the manuscript. DC and KD revised the subsequent drafts of the manuscript with consultations from LR and TK. EN and $Y L$ undertook the data management and statistical analyses. All authors read and approved the final manuscript.

\section{Ethics approval and consent to participate}

The University of British Columbia/Providence Health Care Research Ethics Board approved the study, and consent to participate was obtained from each participant

\section{Consent for publication}

Not applicable

\section{Competing interests}

The authors declare that they have no competing interests.

\section{Publisher's Note}

Springer Nature remains neutral with regard to jurisdictional claims in published maps and institutional affiliations.

\section{Author details}

${ }^{1}$ British Columbia Centre on Substance Use, British Columbia Centre for Excellence in HIV/AIDS, St. Paul's Hospital, 608-1081 Burrard Street, Vancouver, BC V6Z 1Y6, Canada. ${ }^{2}$ Department of Family Practice, St. Paul's Hospital, University of British Columbia, 608-1081 Burrard Street, Vancouver, BC V6Z 1Y6, Canada. ${ }^{3}$ Department of Medicine, St. Paul's Hospital, University of British Columbia, 608-1081 Burrard Street, Vancouver, BC V6Z 1Y6, Canada. ${ }^{4}$ School of Public Policy, SFU Harbour Centre, Simon Fraser University, 515 West Hastings Street, Suite 3271, Vancouver, BC V6B 5K3, Canada.

Received: 19 January 2018 Accepted: 13 March 2018

Published online: 20 March 2018

\section{References}

1. Boivin JF, Roy E, Haley N, Galbaud du Fort G. The health of street youth: a Canadian perspective. Can J Public Health. 2005:96:432-7.

2. Small W, Fast D, Krusi A, Wood E, Kerr T. Social influences upon injection initiation among street-involved youth in Vancouver, Canada: a qualitative study. Subst Abuse Treat Prev Policy. 2009;4:8.

3. Marshall BD, Grafstein E, Buxton JA, Qi J, Wood E, Shoveller JA, Kerr T. Frequent methamphetamine injection predicts emergency department utilization among street-involved youth. Public Health. 2012;126:47-53.

4. Edidin JP, Ganim Z, Hunter SJ, Karnik NS. The mental and physical health of homeless youth: a literature review. Child Psychiatry Hum Dev. 2012;43:354-75

5. Slesnick N, Prestopnik J. Dual and multiple diagnosis among substance using runaway youth. Am J Drug Alcohol Abuse. 2005;31:179-201.

6. Chelvakumar G, Ford N, Kapa HM, Lange HLH, McRee AL, Bonny AE. Healthcare barriers and utilization among adolescents and young adults accessing services for homeless and runaway youth. J Community Health. 2017:42:437-43.

7. Ensign J, Bell M. Illness experiences of homeless youth. Qual Health Res. 2004;14:1239-54.

8. Ensign J, Gittelsohn J. Health and access to care: perspectives of homeless youth in Baltimore City, U.S.A. Soc Sci Med. 1998;47:2087-99.

9. Salit SA, Kuhn EM, Hartz AJ, Vu JM, Mosso AL. Hospitalization costs associated with homelessness in New York City. N Engl J Med. 1998;338:1734-40.

10. Mackelprang $\mathrm{JL}$, Qiu Q, Rivara FP. Predictors of emergency department visits and inpatient admissions among homeless and unstably housed adolescents and young adults. Med Care. 2015;53:1010-7.

11. Medlow S, Klineberg E, Steinbeck $K$. The health diagnoses of homeless adolescents: a systematic review of the literature. J Adolesc. 2014;37: 531-42.

12. Hwang SW, Tolomiczenko G, Kouyoumdjian FG, Garner RE. Interventions to improve the health of the homeless: a systematic review. Am J Prev Med. 2005;29:311-9.

13. Wood E, Stoltz JA, Montaner JS, Kerr T. Evaluating methamphetamine use and risks of injection initiation among street youth: the ARYS study. Harm Reduct J. 2006;3:18.

14. Palepu A, Strathdee SA, Hogg RS, Anis AH, Rae S, Cornelisse PG, Patrick DM, O'Shaughnessy MV, Schechter MT. The social determinants of emergency department and hospital use by injection drug users in Canada. J Urban Health. 1999;76:409-18.

15. Hodgson KJ, Shelton KH, van den Bree MB, Los FJ. Psychopathology in young people experiencing homelessness: a systematic review. Am J Public Health. 2013;103:e24-37.

16. Kozloff N, Adair CE, Lazgare LI, Poremski D, Cheung AH, Sandu R, Stergiopoulos V. "Housing first" for homeless youth with mental illness. Pediatrics. 2016;138(4):e20161514.

17. Cheung A, Somers JM, Moniruzzaman A, Patterson M, Frankish CJ, Krausz M, Palepu A. Emergency department use and hospitalizations among homeless adults with substance dependence and mental disorders. Addict Sci Clin Pract. 2015;10:17.

18. Hodgson KJ, Shelton KH, van den Bree MB. Mental health problems in young people with experiences of homelessness and the relationship with health service use: a follow-up study. Evid Based Ment Health. 2014;17:76-80. 
19. Gryczynski J, Schwartz RP, O'Grady KE, Restivo L, Mitchell SG, Jaffe JH. Understanding patterns of high-cost health care use across different substance user groups. Health Aff (Millwood). 2016;35:12-9.

20. Nyamathi A, Hudson A, Greengold B, Leake B. Characteristics of homeless youth who use cocaine and methamphetamine. Am J Addict. 2012;21:243-9.

21. Riley ED, Evans JL, Hahn JA, Briceno A, Davidson PJ, Lum PJ, Page K. A longitudinal study of multiple drug use and overdose among young people who inject drugs. Am J Public Health. 2016;106:915-7.

22. Rudd RA, Seth P, David F, Scholl L. Increases in drug and opioid-involved overdose deaths-United States, 2010-2015. MMWR Morb Mortal Wkly Rep. 2016;65:1445-52

23. British Columbia Coroners Service. Illicit drug overdose deaths in BC, January 1 , 2007-March 31, 2017. Vancouver: British Columbia Coroners Service; 2017. http://www2.gov.bc.ca/assets/gov/public-safety-and-emergency-services/ death-investigation/statistical/illicit-drug.pdf. Accessed 4 May 2017.

24. Warner-Smith M, Darke S, Day C. Morbidity associated with non-fatal heroin overdose. Addiction. 2002;97:963-7.

25. Marshall BD, Green TC, Yedinak JL, Hadland SE. Harm reduction for young people who use prescription opioids extra-medically: obstacles and opportunities. Int J Drug Policy. 2016;31:25-31.

26. Mancini MA, Linhorst DM. Harm reduction in community mental health settings. J Soc Work Disabil Rehabil. 2010;9:130-47.

27. Smith T, Hawke L, Chaim G, Henderson J. Housing instability and concurrent substance use and mental health concerns: an examination of Canadian youth. J Can Acad Child Adolesc Psychiatry. 2017;26:214-23.

\section{Submit your next manuscript to BioMed Central and we will help you at every step:}

- We accept pre-submission inquiries

- Our selector tool helps you to find the most relevant journal

- We provide round the clock customer support

- Convenient online submission

- Thorough peer review

- Inclusion in PubMed and all major indexing services

- Maximum visibility for your research

Submit your manuscript at www.biomedcentral.com/submit 